\title{
Pulmonary congenital cystic adenomatoid malformation involving upper lobe with successful surgical management
}

\author{
Rajiv Garg1', S. Saheer ${ }^{1}$, Ghulam Hassan', Ashish Wakhlu², Madhumati Goel ${ }^{3}$, \\ ${ }^{1}$ Department of Pulmonary Medicine, CSM Medical University, UP, Lucknow, India \\ ${ }^{2}$ Department of Pediatric Surgery, CSM Medical University, UP, Lucknow, India \\ ${ }^{3}$ Department of Pathology, CSM Medical University, UP, Lucknow, India
}

\section{ABSTRACT}

A four-week-old infant born after a normal vaginal delivery presented with dyspnea of one month duration. His radiologic evaluation showed multiple cystic lesions involving the left upper lobe, although lower lobe is the usual site. It was removed after pnemonectomy and the final pathological diagnosis was congenital cystic adenomatoid malformation (type II). The postoperative follow up showed excellent recovery and normal development of the child.

Key Words: Congenital cystic adenomatoid malformation of lung, congenital diseases.

\section{INTRODUCTION}

Congenital cystic adenomatoid malformation of the lung is a rare disorder with a reported incidence of 1 in 25,000-35,000 pregnancies ${ }^{1}$ and was recognized as a distinct entity of cystic lung disease by Staerk in $1897^{2}$. It is characterised by overgrowth of terminal bronchiolar type tubular structures and lack of mature alveoli ${ }^{3}$ as a consequence of abnormal embryogenesis during the first 6-7 weeks of pregnancy ${ }^{4,5}$. Usually lower lobes are involved ${ }^{6}$, however, in our case, unusual finding was the left upper lobe involvement. It comprises of a heterogeneous group of cystic and non-cystic lung lesions classified into three types by Stocker et al. in $1977^{4}$ on the basis of cyst size and macroscopic appearance. We report one such case belonging to Type II with favourable surgical outcome.

Address for correspondence: DR. Rajiv Garg. MD Associate Professor, Department of pulmonary medicine CSM Medical University, UP, Lucknow, India-226003 Phone No: +919415002386

E-mail: rajivkgmc@gmail.com

DOI: $10.5530 /$ ijmedph.4.2011.10

\section{CASE REPORT}

A four-week- old male infant weighing $2.3 \mathrm{Kg}$ was referred to our department with complains of respiratory distress and poor feeding since birth. He was born full term after a normal vaginal delivery out of nonconsanguineous marriage. There was no significant family history from the maternal or paternal side. On examination the child was tachypneic. Examination of chest revealed decreased breath sounds on the left side. Chest radiograph showed multiple cystic lesions in all three zones of left lung with mediastinal shift towards opposite side (Figure 1). Computed tomography of thorax revealed multiple cystic lesions involving left upper lobe with contralateral mediastinal shift (Figure 2). The patient was posted for surgery and left pneumonectomy done without any complications. The child showed clinical improvement in the postoperative period and there was normalisation of herniated lung (Figure 3). Grossly the specimen measured $6.5 \times 5.0 \times 0.8 \mathrm{~cm}$ with multiple loculi $/$ septae inside (Figure 4). Microscopically, the section showed lung parenchyma with numerous thin walled cystic bronchioles lined by columnar epithelium with absence of bronchial cartilage and mucous cells (Figure 5). After correlation of clinical, radiological and pathological findings a final diagnosis was made. The patient is under 


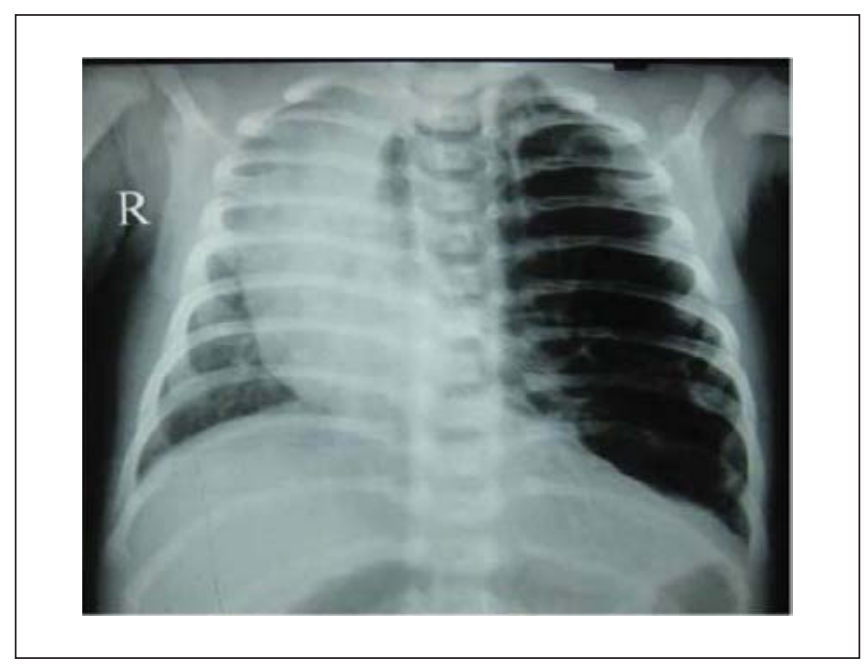

Figure 1: Admission chest radiograph showing multiple cystic lesions in left lung with mediastinal shift to right

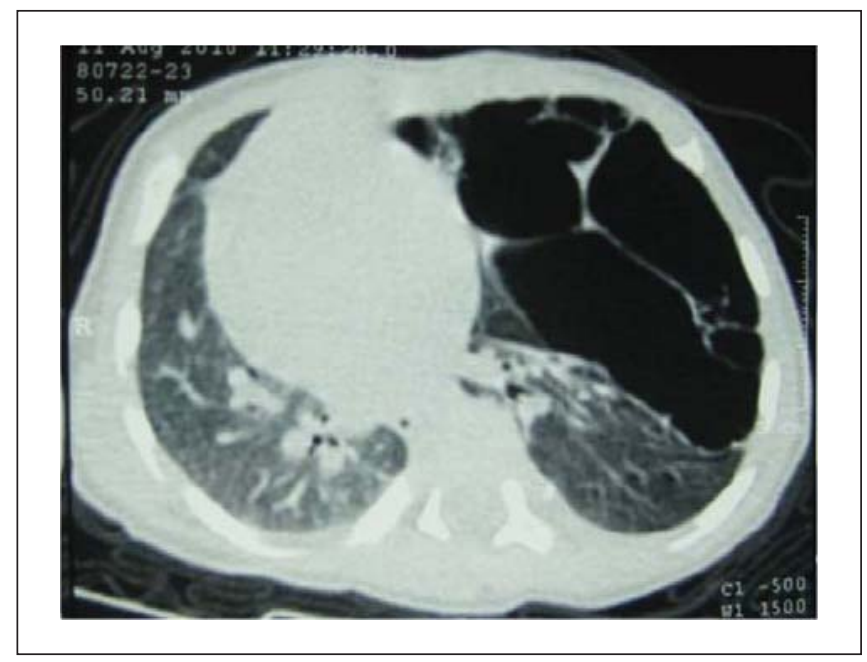

Figure 2: Computed Tomography of thorax revealing multiple cystic lesions involving left upper lobe with contra lateral mediastinal shift

our regular follow up and is asymptomatic with normal milestones.

\section{DISCUSSION}

Also known as congenital pulmonary airway malformation, it is a developmental hamartomatous abnormality of the lung with adenomatoid proliferation of cysts resembling bronchioles, and it was first reported in 1949 by Ch'in and Tang? Et Etiology is unknown and it is proposed to result from focal arrest in fetal lung development before the seventh week of gestation secondary to variety of pulmonary insults. Depending on the number and size of cysts three types have been described by Stocker'. Type I (macrocystic type) is the most common and accounts for 50 to $70 \%$ of cases and characterised by multiple

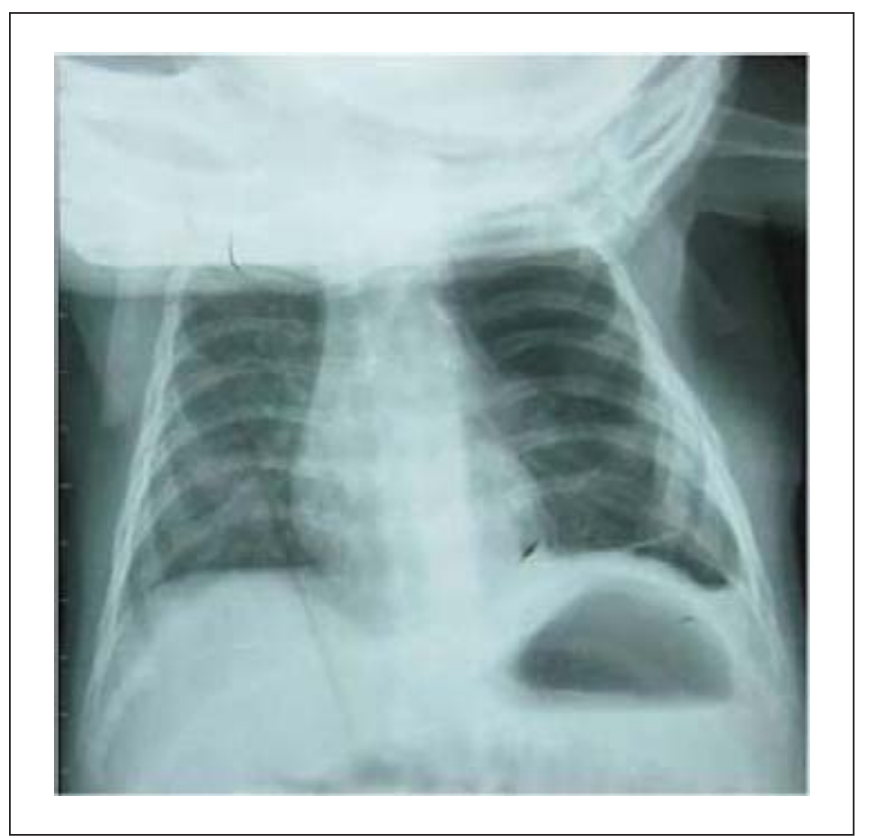

Figure 3: Postoperative chest $\mathrm{x}$-ray showing normalisation of herniated lung

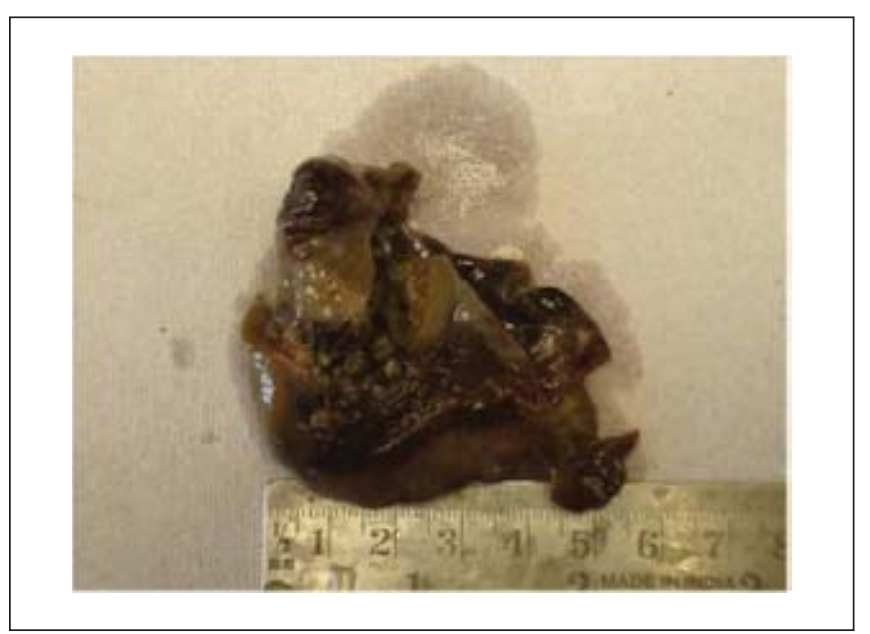

Figure 4: Photograph of the excised specimen

large cysts or a single dominate, often, multiloculated cyst. This type has a very favourable outcome. Type II (microcystic type) accounts for $40 \%$ of the postnatal cases and shows numerous small uniformly shaped cysts with diameters ranging from 0.5 to $2 \mathrm{~cm}$. This form is commonly associated with other congenital cardiac, -renal, -intestinal and skeletal anomalies. The prognosis depends on the severity of associated anomalies. Type III (solid type) is the least common type accounting for only $10 \%$ of cases and consists of a bulky firm, solid mass with cysts less than $0.5 \mathrm{~cm}$ in diameter. Large lesions can cause mediastinal shift and can affect cardiac function leading to development of hydrops foetalis. Prognosis is poor especially when the later is present. 


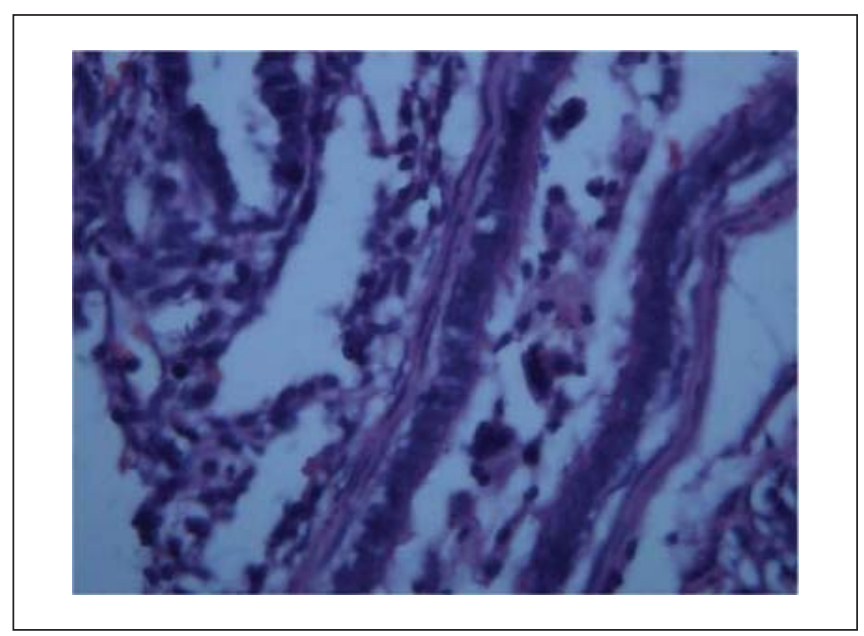

Figure 5: Photomicrograph showing lung parenchyma with numerous thin walled cystic bronchioles lined by columnar epithelium with absence of bronchial cartilage and mucous cells (H\&E stain $X$ original magnification $X 400$ )

The condition presents within first year of life or can be detected prenatally with the help of prenatal ultrasound. About $70 \%$ of cases present in the first month of life with respiratory distress. Occasionally it is discovered later in life, usually with chronic or recurrent pulmonary infections. The differential diagnosis includes congenital lobar emphysema, bronchogenic cyst, congenital diaphragmatic hernia, pulmonary interstitial emphysema and pulmonary sequestration. This is differentiated from other congenital diseases by absence of bronchial cartilage (unless trapped within the lesion), absence of bronchial tubular glands, presence of tall columnar mucinous epithelium, overproduction of terminal bronchiolar structures without alveolar differentiation and massive enlargement of the affected lobe that displaces other thoracic structures. ${ }^{8}$ The usual appearance on chest skiagram is mass containing air filled cysts. The other radiological signs include mediastinal shift, pleural and pericardial effusions and pneumothorax. Computed tomography of thorax reveals mutilocular cystic lesions with thin walls surrounded by normal lung parenchyma, however superimposed infection may complicate the appearance resulting in air fluid levels. Treatment of choice is elective lobectomy. Surgery can be delayed if the patient is asymptomatic or the cyst is resolving. The prognosis is excellent and following lobectomy the remaining lung grows and expands well enough so that lung volume and pulmonary function tests return to normal ${ }^{9}$, as was the outcome of our patient.

\section{REFERENCES}

1. Laberge JM, Flageole H, Pugash D, Khalife S, Blair G, Filiatrault D et al.: Outcome of the prenatally diagnosed congenital cystic adenomatoid lung malformation: A Canadian experience. Fetal Diagn Ther 2001; 16: 178-186.

2. Kwittken J, Reiner L. Congenital cystic adenomatoid malformation of the lung. Pediatrics 1962; 30:759-768.

3. Reynolds M. Congenital lesions of the lung; in: Shields TW, LoCicero J, Pojournal RB (eds): General Th oracic Surgery, 5th ed. Philadelphia, Lippincott Williams \& Wilkins, 2000, pp 937-52.

4. Stocker JT, Drake RM: Congenital cystic adenomatoid malformation of the lung. Classification and morphologic spectrum. Hum Pathol 1977;8: 155-171.

5. Adzich NS, Harrison MR, Flake AW, Howell LJ, Golbus MS, Filly RA: Fetal surgery for cystics adenomatoid malformation of the lung. J Pediatr Surg 1993; 28:806-812.

6. Loachimescu OC, Mehta AC: From cystic pulmonary airway malformation, to bronchioloalveolar carcinoma and adenocarcinoma of the lung. Eur Respir J 2005; 26;1181-1187.

7. Ch'in Y, Tang M: Congenital adenomatoid malformation of one lobe of a lung with general anasarca. Arch Pathol Lab Med 1949; 48:221-229.

8. Cass DL, Quijournal TM, Yang EY et al. Increased cell proliferation and decreased apoptosis characterize congenital cystic adenomatoid malformation of the lung. J Pediatr Surg 1998; 33:1043-7.

9. Filler J. Effects upon pulmonary function of lobectomy performed during childhood. Am Rev Respir Dis 1964; 89:801-810. 